\title{
Factors associated with the number of filled teeth in adolescents from public schools: a cohort study
}

\author{
Rafaela Oliveira PILECCO(a) ID \\ Leonardo da Silva GODOIS(a) ID \\ Marília Cunha MARONEZE(a) iD \\ Fernanda Ruffo ORTIZ(b) \\ Thiago Machado ARDENGHI(a) iD \\ (a) Universidade Federal de Santa Maria - \\ UFSM, School of Dentistry, Department of \\ Stomatology, Santa Maria, RS, Brazil. \\ (b) Universidade Federal de Minas Gerais - \\ UFMG, School of Dentistry, Department of \\ children and adolescent's oral health, Belo \\ Horizonte, MG, Brazil
}

Declaration of Interests: The authors certify that they have no commercial or associative interest that represents a conflict of interest in connection with the manuscript.

Corresponding Author:

Thiago Machado Ardenghi

E-mail: thiardenghi@hotmail.com

hHtps://doi.org/10.1590/1807-3107bor-2019.vol33.0124

Submitted: August 25, 2019

Accepted for publication: November 6, 2019

Last revision: December 6, 2019

\begin{abstract}
This study aimed to assess the association of demographic conditions, socioeconomic status, clinical variables, and psychosocial factors with the number of filled teeth in adolescents from public schools. This cohort study comprised 1,134 12-year-old adolescents enrolled in public schools in Santa Maria, Brazil, in 2012. They were followed-up in 2014, where 743 individuals were reassessed (follow-up rate of $65.52 \%$ ) for the number of filled teeth. Data were collected via dental examinations and structured interviews. Demographic and socioeconomic characteristics were collected from parents or legal guardians. The psychosocial factor comprised students' subjective measurement of happiness (Brazilian version of the Subjective Happiness Scale - SHS). Dental examinations were performed to assess the number of filled teeth through decay, missing, and filled teeth index (DMF-T). Unadjusted and adjusted Poisson regression analyses were performed to assess the association between baseline variables and filled teeth at follow-up. The number of filled teeth in 2012 and 2014 were 193 (17.02\%) and $235(31.63 \%)$, respectively. The incidence of filled teeth in 2014 was 42 (5.65\%). Adolescents with untreated dental caries, those who visited the dentist in the last 6 months, those that exhibited being happier, and those who had filled teeth at baseline were associated with a higher number of filled teeth at follow-up. We conclude that the number of filled teeth in adolescents was influenced by clinical and psychosocial factors, emphasizing the need to focus on oral health policies in individuals with higher disease burden and those who feel psychologically inferior.
\end{abstract}

Keywords: Adolescent; Dental Care; Dental Health Services; Dentistry, Operative; Psychologicy.

\section{Introduction}

According to World Health Organization (WHO), ${ }^{1}$ adolescence is the period between 10 and 19 years. This transition phase to adult life is characterized by innumerable physical, hormonal, sexual, emotional, and intellectual changes. Therefore, adolescents are exposed to many resources that may influence their transition to adulthood and impact their health and positive experiences. ${ }^{2}$ 
Data from the last national survey conducted in Brazil showed decay, missing teeth, and a filled teeth index (DMF-T) of 2.07 in 12-year-old adolescents with a D-component of $1.21 .{ }^{3}$ Additionally, $13.6 \%$ of adolescents between 15 and 19-years had never visited a dentist. The inequality in the access to oral health services also has been described for adults., ${ }^{4,5}$ Individuals who do not regularly receive dental services generally have fewer filled teeth and a higher number of decayed teeth than individuals who visit dentists regularly. ${ }^{6}$ Furthermore, adolescents with low socioeconomic status, low mother's education level, and those with extremely poor backgrounds, presented higher levels of dental caries than their counterparts. ${ }^{78,9}$ Therefore, the use of health services can prevent tooth loss due to dental caries through restorative treatment for individuals in disadvantaged social groups. ${ }^{10}$.

Previous studies have shown that untreated dental caries have a negative impact on oral health-related quality of life (OHRQoL) of adolescents. ${ }^{8,11,12,13,14}$ Thus, the American Academy of Pediatric Dentistry (AAPD) recommends restorative treatment in cases of dental caries, where the process of demineralization and progression of the lesion is intense. ${ }^{15}$ The restorative treatment can remove cavities, prevent the progression of tooth demineralization, restore tooth structure, and prevent the spread of the infection to the dental pulp. ${ }^{16}$ Thus, such dental treatment can reduce oral problems and functional limitations, improving the OHRQoL of adolescents. ${ }^{17}$

Previous studies have also found an association between clinical, socioeconomic, demographic, psychosocial factors, and oral conditions in adolescents. ${ }^{13,18,19,20,21}$ However, few studies have explored the factors that influence adolescents to go in for restorative treatment. ${ }^{9,22}$ The few studies that have been conducted focused on evaluating the association between individual and contextual factors regarding the presence of untreated caries and lesions, ${ }^{9}$ and the influence of factors on the use of dental services; ${ }^{22,23}$ however, none of these assessed the factors associated with the use of restorative treatment. Further, no study has evaluated the influence of psychosocial factors on the presence of filled teeth. Therefore, the aim of this study is to assess whether demographic conditions, socioeconomic status, clinical variables, and psychosocial factors influence the presence of filled teeth in adolescents. Our conceptual hypothesis is that adolescents with low socioeconomic status, less psychosocial factors, and limited availability of dental services will have fewer filled teeth.

\section{Methodology}

\section{Design and ethical aspects}

This is a cohort study that assessed the oral health status of adolescents in Santa Maria, a city in southern Brazil. In 2012, when the first data collection took place, the city had approximately 261,031 individuals. The study protocol was reviewed and approved by the Committee of Ethics in Research of the Federal University of Santa Maria (CAAE 0127.0.243.000-11). All subjects consented to participate and their parents or guardians signed a written informed consent form.

\section{Sample}

A total of 20 schools were randomly selected in a two-stage sampling procedure from a total of 39 public schools, located in 5 administrative regions of the city (north, south, east, west, and center). Classes from those schools were again randomly selected. All 12-years-old adolescents enrolled in the 20 public schools previously selected were eligible (except those with any degree of mental or physical disability) and invited to participate. A total of 1,134 students were evaluated in 2012.

The estimated sample size was calculated by proportion of restoration between adolescents (47\%) with odds ratio of $1.74(p=0.00),{ }^{24} 95 \%$ confidence interval), $80 \%$ power statistic, proportion 2:1 (exposed: non-exposed), and additional $30 \%$ of losses. The minimum sample size was identified as 662 participants. This study was part of a major data collection; therefore, the number of individuals assessed is larger than the minimum required sample size. ${ }^{18,21,25}$

\section{Data collection}

Data were collected via dental examinations and structured interviews conducted between March and October 2012 by four examiners and three 
interviewers in the selected schools. The feasibility of the questionnaire was verified by administering the questionnaire again to $10 \%$ of the adolescents in the sample. The examiners were trained and calibrated to assess clinical variables in a 36 hour program that included theory-based activities and a trial examination of 20 adolescents. These adolescents were examined twice by the same examiner with an interval of two weeks. A Gold Standard led the process of training and calibration of the examiner. The examiners used a plain mouth mirror, gauze, and probe in a classroom with natural light, according to the international criteria standardized by WHO for oral health surveys. ${ }^{26}$ The DMF-T index was used to gather data on untreated dental caries and filled permanent teeth. The participants of the study that presented a need for dental treatment were referred to the dental clinic of Federal University of Santa Maria.

Demographic and socioeconomic characteristics were collected from parents or legal guardians using a structured questionnaire. The same questionnaire was used in a previous study ${ }^{27}$ and includes information on gender, skin color, fathers' educational level, household income, and oral service use. Skin color was recorded as per the Brazilian Institute of Geography and Statistics (white, black, mixed, or other) and the answers were dichotomized as "white" or "nonwhite". ${ }^{28}$ Fathers' educational level was divided into two levels: high (fathers who had completed eight years of formal instruction) and low education level (those that had less than eight years of formal instruction). Household income was measured based on the average monthly income of all individuals living in the adolescent's house; and later analyzed by median. The values approximately corresponded to US 450 dollars $(\mathrm{R} \$ 1,000)$ during the period of data collection. The visit to the dentist was recorded by the question "Has your child visited a dentist in the last 6 months?", and the possible answers were "yes" or "no". When the parents said children had already visited the dentist, they were asked the reason of the last appointment. The possible answers were: "toothache", "mouth pain", "dental trauma", "exam and routine" or "others". The responses were recorded as "checkup" to answers of exam and routine and "toothache" for the others. Parents' perception about children's oral health was recorded with the question: "Would you say that your child's oral health is___" and the possible answers were "Excellent," "good," "fair," and "poor." The responses were categorized as "excellent/good" or "fair/poor".

Subjective happiness measured in this study was collected by the Brazilian version of the Subjective Happiness Scale ${ }^{29,30}$. This scale involves four items regarding positive and negative aspects, encompassing whether the person seems happy or unhappy. The adolescents answered the questions: a) "In general, I consider myself...", b) "Compared to most of my friends, I consider myself...", c) "Some people are usually very happy. They enjoy life, no matter what. How does this phrase look like to you?", and d) "Some people are usually not very happy. Although they are not sad, they never seem to be as happy as they could be. How does this phrase look like to you?" Responses ranged from 0 to 7 ; the higher the values, the happier the person.

The second phase of data collection was performed between October 2014 and June 2015. All the adolescents who participated in phase one were invited and their parents and guardians consented to their participation. A total of 743 adolescents participated in the second data collection considering the outcome of this study, resulting in a follow-up rate of $65.52 \%$. The students were approached by reaching out to the schools. Phone calls were made when it was not possible to reach the adolescent. The same variables under the same methodological protocol as phase one were gathered again. The outcome of the second phase was the number of filled teeth assessed in 2014 through the F-component of the DMF-T index.

\section{Statistical analyses}

Data were analyzed using the software STATA 14.0 (Stata Corporation, College Station, TX, USA). Descriptive analyses were performed to provide information about demographic, socioeconomic, clinical, and psychosocial characters of the sample at baseline and at follow up. The differences between the participants and non-participants were evaluated by the Chi-square test and sensitivity analysis using the Monte Carlo simulation. 
Filled teeth were summarized by the mean and standard deviation (SD). The outcome of this study was the number of filled teeth (corresponding ' $F^{\prime}$ component of the DMF-T index) assessed in 2014. Teeth that presented restorations of composite, amalgam, or glass ionomer cement were considered as filled.

Unadjusted and adjusted Poisson regression models were performed to assess the association between predictors' factors at baseline with filled teeth at follow up. In the unadjusted analysis, variables with p-value $<0.20$ were included in the adjusted model. Household income was maintained in the final model regardless of the statistical significance, considering theoretical questions.

The Ratio Rate was used to measure the degree of association, which corresponds to the ratio of the arithmetic mean of filled teeth between exposed/unexposed groups according to different predictors. In the adjusted analysis, associations were considered with $95 \%$ confidence interval and $p$ value $<0.05$. The bootstrap method was also used to estimate the standard errors as well as the $\mathrm{CI}$ of the estimated effects. For this estimation, we used 500 resamples of size 10,000 .

\section{Results}

A total of 1,134 adolescents participated in the baseline, with a mean age of 11.94 (SD: 0.65) years. A total of 743 were re-evaluated in 2014 (follow-up rate of $65.52 \%$ ). The mean age of the sample at follow up was 14.33 (SD: 0.69) years. Reasons for non-participation were mainly refusal to take part in the study or that the participants could not be found. In 2012, the kappa values for inter- and intra-examiner agreement for clinical variables varied between 0.77 to 0.82 and 0.79 to 0.85 , respectively. In 2014 , the values varied between 0.81 to 0.90 and 0.81 to 0.87 , respectively.

Demographic, socioeconomic, clinical, and psychosocial data of the participants are presented in Table 1 . The majority of the participants were females, white, had fathers who had finished elementary school, and had a household income $\geq 1,000$ Brazilian Reais. Approximately half of the sample had not visited the dentist in the last 6 months and for most of them (73.81\%), their last dental checkup was at baseline. In the follow-up, $45.47 \%$ of the participants had visited the dentist in the last 6 months. The prevalence of untreated dental caries at baseline was $42,06 \%$. The mean scores on the Subjective Happiness Scale (SHS) was 5.23 (SD: 0.90). The number of filled teeth in 2012 and 2014 was 193 (17.02\%; mean=0.26; SD: 0.66) and 235 (31.63\%; mean $=0.25$; SD: 0.62). Comparing the participants with the non-participants at baseline and at follow up (Table 1), there were no statistical differences for sex $(p=0.28)$, skin color $(p=0.48)$, father's education $(p=0.36)$, household income $(p=0.22)$, dentist visit $(p=0.09)$, reason for visit $(p=0.35)$, parents' perception $(p=0.67)$, subjective happiness scale score $(0.59)$, and filled teeth $(p=0.64)$. There was a difference in the variable untreated dental caries $(p=0.04)$. However, we performed a sensitivity analysis using the Monte Carlo simulation and we verified that this difference did not influence our results.

Table 2 presents the results of the Poisson regression analysis between baseline variables and number of filled teeth at follow-up. According to an unadjusted analysis, sex, skin color, age, fathers' education, dentist visit, reason for visit, untreated dental caries, parent's perception of adolescents' oral health, subjective happiness, and number of filled teeth at baseline were associated to number of filled teeth at follow-up $(\mathrm{p}<0.05)$.

In the adjusted Poisson regression analysis, dentist visit, untreated dental caries, happiness, and number of filled teeth at baseline was associated with the number of filled teeth at follow up. Adolescents who did not visit the dentist in the last 6 months showed a lower mean of filled teeth $(\mathrm{RR}=0.75 ; 95 \% \mathrm{CI} 0.58-0.96)$. Individuals with untreated dental caries showed a 2.43 times higher mean of filled teeth $(R R=2.43$; 95\%CI 1.88-3.15) than those who had untreated dental caries. Adolescents who felt happier showed a lesser number of filled teeth ( $R R=0.84 ; 95 \% C I$ 0.73-0.96) when compared with their counterparts; those with filled teeth at baseline had a higher number of filled teeth at follow-up $(\mathrm{RR}=1.93 ;$ 95\%CI 1.69-2.20) (Table 2).

\section{Discussion}

This cohort study aimed to evaluate the influence of demographic conditions, socioeconomic status, clinical variables, and psychosocial factors on the 
Table 1. Descriptive analysis of the sample (Santa Maria, Brazil, 2012 and 2014.)

\begin{tabular}{|c|c|c|c|c|}
\hline \multirow{2}{*}{ Variables } & Baseline & Follow-up & Dropout & \multirow{2}{*}{$\mathrm{p}$-value } \\
\hline & $\mathrm{n}(\%) /$ Mean $(\mathrm{SD})$ & $\mathrm{n}(\%) /$ Mean(SD) & $(n=391)$ & \\
\hline Sex & & & & 0.28 \\
\hline Female & $610(53.79)$ & $391(52.62)$ & $219(56.01)$ & \\
\hline Male & $524(46.21)$ & $352(47.38)$ & 172 (43.99) & \\
\hline Skin color* & & & & 0.48 \\
\hline White & $863(77.54)$ & $573(78.17)$ & $290(76.32)$ & \\
\hline Non-white & $250(22.46)$ & $160(21.83)$ & $90(23.68)$ & \\
\hline Father's education* & & & & 0.36 \\
\hline$\geq 8$ years & $628(60.74)$ & $408(59.74)$ & $220(62.68)$ & \\
\hline$<8$ years & $406(39.26)$ & $275(40.26)$ & $131(37.32)$ & \\
\hline Household income* & & & & 0.22 \\
\hline$\geq$ US 450 & $556(53.67)$ & $360(52.33)$ & $196(52.32)$ & \\
\hline$<$ US 450 & $480(46.33)$ & $328(47.67)$ & $152(43.68)$ & \\
\hline Dentist visit (last 6 months)* & & & & 0.09 \\
\hline Yes & $514(47.33)$ & $326(45.47)$ & $188(50.95)$ & \\
\hline No & $572(52.67)$ & $391(54.53)$ & 181 (49.05) & \\
\hline Reason for visit* & & & & 0.35 \\
\hline Check-up & $778(73.81)$ & $503(72.90)$ & $275(75.55)$ & \\
\hline Toothache & $276(26.19)$ & $187(27.10)$ & $89(24.45)$ & \\
\hline Untreated dental caries & & & & 0.04 \\
\hline Without & $657(57.94)$ & $447(60.16)$ & $210(53.71)$ & \\
\hline With & $477(42.06)$ & $296(39.84)$ & $181(46.29)$ & \\
\hline Parents' perception* & & & & 0.67 \\
\hline Excellent/good & $719(65.13)$ & 469 (64.69) & $250(65.96)$ & \\
\hline Fair/poor & $385(34.87)$ & $256(35.31)$ & $129(34.04)$ & \\
\hline Subjective Happiness Scale (continuous variable) & $5.23(0.90)$ & $5.25(0.90)$ & $5.22(0.88)$ & 0.59 \\
\hline Filled teeth & & & & 0.64 \\
\hline Yes & $193(17.02)$ & $0.25(0.62)$ & $0.27(0.72)$ & \\
\hline No & $941(82.98)$ & & & \\
\hline
\end{tabular}

*Missing data; US 450 which approximately corresponded to R\$1,000.

number of filled teeth of 14-years-old adolescents. Our results suggest that restorative treatment was influenced by clinical variables and psychosocial factors. Adolescents who had untreated dental caries and filled teeth at baseline presented higher number of filled teeth at follow up. In addition, those who did not visit the dentist regularly and who felt happier during the baseline showed less number of filled teeth at follow up.

The presence of untreated dental caries was associated with a higher number of filled teeth in adolescents at follow-up interviews. Infrequently, oral health services during childhood may result in an accumulation of dental needs throughout life. ${ }^{31}$ It was found that individuals present a higher incidence of caries lesions, owing to which they seek treatment to manage the pain..$^{31}$ Andersen proposed a model to understand the contextual and individual factors that influence the use of health services. ${ }^{32}$ According to the model, there are predisposing factors that exist before the illness, enabling factors that enable the provision of seeking treatment, and need factors based on clinical evaluation and/or self-evaluation according to the need for treatment. ${ }^{32}$ Adolescents and young adults, even if they are not aware of their dental conditions and the need for treatment, had a higher number of untreated teeth. ${ }^{33}$ Furthermore, children with untreated carious lesions 
Table 2. Unadjusted and adjusted Poisson regression analysis between filled teeth (follow-up) and baseline variables (Santa Maria, Brazil, 2012 and 2014).

\begin{tabular}{|c|c|c|c|c|}
\hline \multirow{2}{*}{ Baseline variables } & \multicolumn{4}{|c|}{ Filled Teeth (follow-up) } \\
\hline & $\mathrm{RR}_{\text {crude }}(95 \% \mathrm{Cl})$ & $\mathrm{p}$-value & $\operatorname{RR}_{\text {adi }}(95 \% \mathrm{Cl})$ & $p$-value \\
\hline Sex & & 0.200 & & 0.636 \\
\hline Female & 1 & & 1 & \\
\hline Male & $1.13(0.94-1.37)$ & & $1.07(0.81-1.40)$ & \\
\hline Skin Color & & 0.106 & & 0.48 \\
\hline White & 1 & & 1 & \\
\hline Non-white & $0.82(0.64-1.04)$ & & $0.88(0.62-1.26)$ & \\
\hline Age & $1.31(1.13-1.51)$ & 0.000 & $1.01(0.82-1.25)$ & 0.888 \\
\hline Father's education & & 0.116 & & 0.314 \\
\hline$\geq 8$ years & 1 & & 1 & \\
\hline$<8$ years & $1.17(0.96-1.42)$ & & $1.04(0.96-1.12)$ & \\
\hline Household income & & 0.204 & & 0.139 \\
\hline$\geq$ US 450 & 1 & & 1 & \\
\hline$<$ US 450 & $0.88(0.72-1.07)$ & & $0.79(0.58-1.08)$ & \\
\hline Dentist visit & & 0.000 & & 0.022 \\
\hline Yes & 1 & & 1 & \\
\hline No & $0.71(0.59-0.86)$ & & $0.75(0.58-0.96)$ & \\
\hline Reason for visit & & 0.000 & & 0.927 \\
\hline Check-up & 1 & & 1 & \\
\hline Toothache & $1.47(1.20-1.80)$ & & $0.98(0.72-1.35)$ & \\
\hline Untreated dental caries & & 0.000 & & 0.000 \\
\hline Without & 1 & & 1 & \\
\hline With & $3.01(2.46-3.68)$ & & $2.43(1.88-3.15)$ & \\
\hline Parents' perception & & 0.003 & & 0.514 \\
\hline Excellent/good & 1 & & 1 & \\
\hline Fair/poor & $1.34(1.11-1.63)$ & & $1.11(0.81-1.50)$ & \\
\hline Subjective Happiness Scale & $0.87(0.78-0.96)$ & 0.007 & $0.84(0.73-0.96)$ & 0.012 \\
\hline
\end{tabular}

RR: Ratio rate; $\mathrm{Cl}$ : confidence interval; US 450 which approximately corresponded to $\mathrm{R} \$ 1,000$.

are most likely to seek dental care $^{23}$ and search for restorative treatment. Our results are in accordance with Andersen's model, which reports the influence of the need factor in the search for the health service, indicating that adolescents would seek treatment through self-perception, and usually because of painful symptomatology. 32

The presence of filled teeth at baseline was associated with a higher number of filled teeth at follow up. We have included the number of filled teeth at baseline in the model so as to carry out a longitudinal study. The presence of carious lesions is the best predictor of future lesions of dental caries $^{34}$ and it has been shown that individuals with high risk for caries were more likely to receive restorative treatment. ${ }^{24}$ This may further confirm the repetitive restorative process, and the cumulative effect of caries. It also shows that the restorative treatment itself does not reduce disease burden; thus, highlighting the importance of integral care and preventive behaviors.

This study showed that adolescents who did not visit the dentist at baseline presented a lower number of filled teeth at the follow up. This finding is in accordance with another study that demonstrated that adolescents who did not visit the dentist regularly had a higher likelihood of having untreated teeth..$^{35}$ Not visit the dentist generally leads to the non-realization of the restorative treatment, whereas adolescents who had not used dental health services do not have access to any interventions. ${ }^{33}$ Incipient lesions 
can be diagnosed in preventive dental visits; it is also possible to encourage healthy oral habits and health education through such visits. ${ }^{6,15}$ Therefore, individuals who do not visit the dentist regularly are less exposed to oral health advice. They are more likely to visit the dentist in the advanced stages of caries lesions, limiting the accomplishment of the restorative treatment. ${ }^{6,10}$ Additionally, there is no public program for adolescents' oral health in Santa Maria; consequently, these individuals are neglected from getting advice and specific dental assistance, leading to an accumulation of oral health needs and risk behaviors.

Household income and father's education was not associated with the outcome at follow up. Socioeconomic status is a variable that can be understood as a predisposing or enabling factor for the use of dental care. ${ }^{36}$ In general, adolescents with a lower socioeconomic status, visit the dentist less and commonly have less preventive appointments. ${ }^{6,35,36}$ However, the use of dental services does not depend exclusively on the existence of the service itself; it is influenced by factors related to the adolescent's life, such as psychosocial factors..$^{10}$ In such a case, the materialist theory does not influence the number of filled teeth during adolescence. Adolescents reported being happier, presented higher scores in the Subjective Happiness Scale, exhibited lower number of filled teeth at the follow up. Emotional factors have a wide effect in adolescents' oral health behavior. ${ }^{21,37}$ Health behaviors are influenced by psychological factors. Individuals with worse levels of self-perception and self-esteem tend to have more risk behaviors, opting for unhealthy choices, ${ }^{21,38}$ being exposed to diseases and avoiding dental treatments

Furthermore, the association between psychological factors and the use of dental services has already been reported in cross-sectional studies. ${ }^{21,23,39}$ Adolescents with positive self-perception are more likely to make frequent visits to the dentist than those with poorer self-perception. ${ }^{23,39}$ Consequently, in these visits, it is possible to identify preliminary carious lesions, promote and acknowledge healthy oral habits, and ensure more conservative treatment. ${ }^{6}$ The practice of healthy health behaviors is positively influenced by the happiness status; ${ }^{21}$ thus, adolescents who feel happier are more motivated to improve their oral health conditions. Therefore, psychosocial factors are directly related to the use of dental services; especially to restorative treatment. ${ }^{23}$ As health professionals, dentists should pay attention at their patients' psychological well-being because it influences their treatment and behaviors. It is important that the professional act on psychological factors in order to seek integral care. ${ }^{15}$ In addition, we highlight the need of public health programs in favor of improving not only oral health behaviors but also psychological factors in this age group.

Our results should be interpreted with caution as this study has some limitations. Our sample comprised only public school students; however, this cannot be considered a bias since approximately $85 \%$ of the adolescents in Santa Maria study in public schools. Moreover, we assessed only one psychosocial variable; future studies should verify other variables such as fear, anxiety, and depression, and also examine their influence on the presence of filled teeth.

This study is important because it shows that exposure to restorative treatment is influenced not only by clinical factors. It also indicates the need for strategies that encourage dental care in adolescents with a higher disease burden and those who feel psychologically inferior in terms of happiness. Such strategies should encourage adolescents to go in for routine consultations, where it is possible to introduce healthy habits, and prevent the progression of the disease though restorative treatment. This in turn helps in avoiding invasive treatment (e.g. endodontic treatment and tooth extraction). The findings also emphasize the need for interventions to stimulate better self-perception and self-esteem in adolescents, aiming to promote health, since our study demonstrated that psychosocial factors influence adolescents to use restorative treatment. Finally, we highlight the need for interventional studies to improve psychosocial factors in this age group.

\section{Conclusion}

The number of filled teeth was influenced by clinical variables and psychosocial factors. Restorative treatment is a conservative and effective intervention, 
which can resolve oral problems among adolescents. Additionally, the findings highlight the importance encouraging adolescents to seek dental treatment, when necessary.

\section{Acknowledgment}

We thank all the adolescents who participated in this study, the members of Epidemiology Group that collected the data, and the Municipal Education
Authorities from the municipality of Santa Maria, RS, for granting permission to perform this study. This study was financed in part by the Coordenação de Aperfeiçoamento de Pessoal de Nível Superior - Brazil (CAPES) - Finance Code 001. We are also grateful for the financial support of the Conselho Nacional de Desenvolvimento Cientifico e Tecnológico (CNPq: 313458/2018-9), and Fundação de Amparo à Pesquisa do Rio Grande do Sul (FAPERGS: 17/2551-0001083-3).

\section{References}

1. World Health Organization - WHO. Young people's health: a challenge for society: report of a WHO Study Group on Young People and "Health for All by the Year 2000 Geneva: World Health Organization; 1986.

2. Patton GC, Sawyer SM, Santelli JS, Ross DA, Afifi R, Allen NB, et al. Our future: a Lancet commission on adolescent health and wellbeing. Lancet. 2016 Jun;387(10036):2423-78. https://doi.org/10.1016/S0140-6736(16)00579-1

3. Ministério da Saúde (BR). Pesquisa Nacional de Saúde Bucal: resultados. Brasília, DF: Ministério da Saúde; 2012.

4. Cambota JN, Rocha FF. Determinantes das desigualdades na utilização de serviços de saúde: análise para o Brasil e regiões. Pesqui Planej Econ. 2015;45(2):219-42.

5. Peres MA, Iser BP, Boing AF, Yokota RT, Malta DC, Peres KG. [Inequalities in access to and utilization of dental care in Brazil: an analysis of the Telephone Survey Surveillance System for Risk and Protective Factors for Chronic Diseases (VIGITEL 2009)]. Cad Saude Publica. 2012;28 Suppl:s90-100. Portuguese. https://doi.org/10.1590/S0102-311X2012001300010

6. Afonso-Souza G, Nadanovsky P, Chor D, Faerstein E, Werneck GL, Lopes CS. Association between routine visits for dental checkup and self-perceived oral health in an adult population in Rio de Janeiro: the Pró-Saúde Study. Community Dent Oral Epidemiol. 2007 Oct;35(5):393-400. https://doi.org/10.1111/j.1600-0528.2006.00343.x

7. Pattussi MP, Marcenes W, Croucher R, Sheiham A. Social deprivation, income inequality, social cohesion and dental caries in Brazilian school children. Soc Sci Med. 2001 Oct;53(7):915-25. https://doi.org/10.1016/S0277-9536(00)00391-9

8. Peres KG, Peres MA, Araujo CLP, Menezes AMB, Hallal PC. Social and dental status along the life course and oral health impacts in adolescents: a population-based birth cohort. Health Qual Life Outcomes. 2009 Nov;7:95. https://doi.org/10.1186/1477-7525-7-95

9. Vazquez FL, Cortellazzi KL, Kaieda AK, Bulgareli JV, Mialhe FL, Ambrosano GM, et al. Individual and contextual factors related to dental caries in underprivileged Brazilian adolescents. BMC Oral Health. 2015 Jan;15(15):6. https://doi.org/10.1186/1472-6831-15-6

10. Davoglio RS, Aerts DR, Abegg C, Freddo SL, Monteiro L. [Factors associated with oral health habits and use of dental services by adolescentes]. Cad Saude Publica. 2009 Mar;25(3):655-67. https://doi.org/10.1590/S0102-311X2009000300020

11. Chukwumah NM, Folayan MO, Oziegbe EO, Umweni AA. Impact of dental caries and its treatment on the quality of life of 12- to 15-year-old adolescents in Benin, Nigeria. Int J Paediatr Dent. 2016 Jan;26(1):66-76. https://doi.org/10.1111/ipd.12162

12. Feldens CA, Ardenghi TM, Dullius AIS, Vargas-Ferreira F, Hernandez PA, Kramer PF. Clarifying the impact of untreated and treated dental caries on oral health-related quality of life among adolescents. Caries Res. 2016;50(4):414-21. https://doi.org/10.1159/000447095

13. Piovesan C, Marquezan M, Kramer PF, Bönecker M, Ardenghi TM. Socioeconomic and clinical factors associated with caregivers' perceptions of children's oral health in Brazil. Community Dent Oral Epidemiol. 2011 Jun;39(3):260-7. https://doi.org/10.1111/j.1600-0528.2010.00598.x

14. Pulache J, Abanto J, Oliveira LB, Bönecker M, Porras JC. Exploring the association between oral health problems and oral health-related quality of life in Peruvian 11- to 14-year-old children. Int J Paediatr Dent. 2016 Mar;26(2):81-90. https://doi.org/10.1111/ipd.12160

15. American Academy of Pediatric Dentistry - AAPD. Adolescent oral health care: review council: latest revision: 2015 [cited 2018 Dec 7]. Available from: http://www.aapd.org/media/policies_guidelines/g_adoleshealth.pdf

16. American Academy of Pediatric Dentistry - AAPD. Pediatric restorative dentistry; review council: latest revision 2016. [cited 2019 Jan 7]. Available from: http://www.aapd.org/media/Policies_Guidelines/BP_RestorativeDent.pdf

17. Maroneze MC, Ardenghi DM, Brondani M, Unfer B, Ardenghi TM. Dental treatment improves the oral health-related quality of life of adolescents: A mixed-methods approach. Int J Paediatr Dent. 2019. 12548. https://doi.org/10.1111/ipd.12548

18. Rosa GN, Del Fabro JP, Tomazoni F, Tuchtenhagen S, Alves LS, Ardenghi TM. Association of malocclusion, happiness, and oral health-related quality of life (OHRQoL) in schoolchildren. J Public Health Dent. 2016 Mar;76(2):85-90. https://doi.org/10.1111/iphd.12111 
19. Nicolau B, Marcenes W, Bartley M, Sheiham A. A life course approach to assessing causes of dental caries experience: the relationship between biological, behavioural, socio-economic and psychological conditions and caries in adolescents. Caries Res. 2003 Sep-Oct;37(5):319-26. https://doi.org/10.1159/000072162

20. Scheerman JF, Loveren C, Meijel B, Dusseldorp E, Wartewig E, Verrips GH, et al. Psychosocial correlates of oral hygiene behaviour in people aged 9 to 19: a systematic review with meta-analysis. Community Dent Oral Epidemiol. 2016 Aug;44(4):331-41. https://doi.org/10.1111/cdoe.12224

21. Tuchtenhagen S, Bresolin CR, Tomazoni F, Rosa GN, Del Fabro JP, Mendes FM, et al. The influence of normative and subjective oral health status on schoolchildren's happiness. BMC Oral Health. 2015 Jan;15(1):15. https://doi.org/10.1186/1472-6831-15-15

22. Chala S, Silorh K, Abouqal R, Abdallaovi F. [Factors associated with dental care use among a population of Moroccan adolescents]. Rev Stomatol Chir Maxillofac Chir Orale. 2016 Dec;117(6):367-71. French. https://doi.org/10.1016/i.revsto.2016.05.005

23. Piovesan C, Antunes JL, Guedes RS, Ardenghi TM. Influence of self-perceived oral health and socioeconomic predictors on the utilization of dental care services by schoolchildren. Braz Oral Res. 2011 Mar-Apr;25(2):143-9. https://doi.org/10.1590/S1806-83242011005000004

24. Signori C, Laske M, Bronkhorst EM, Huysmans MD, Cenci MS, Opdam NJ. Impact of individual-risk factors on caries treatment performed by general dental practitioners. J Dent. 2019 Feb;81:85-90. https://doi.org/10.1016/i.jdent.2018.12.016

25. Tomazoni F, Vettore MV, Zanatta FB, Tuchtenhagen S, Moreira CH, Ardenghi TM. The associations of socioeconomic status and social capital with gingival bleeding among schoolchildren. J Public Health Dent. 2017 Dec;77(1):21-9. https://doi.org/10.1111/iphd.12166

26. World Health Organization - WHO. Oral health surveys, basic methods. Geneva: World Health Organization; 1997.

27. Piovesan C, Mendes FM, Antunes JLF, Ardenghi TM. Inequalities in the distribution of dental caries among 12-year-old Brazilian schoolchildren. Braz Oral Res. 2011 Jan-Feb;25(1):69-75. https://doi.org/10.1590/S1806-83242011000100012

28. Instituto Brasileiro de Geografia e Estatística - IBGE. Sample's results: work and income. 2018. [cited 2018 Dec 15]. Available from: http://www.sidra.ibge.gov.br

29. LyubomirskyS, Lepper HS. A Measure of Subjective Happiness: Preliminary Reliability and Construct Validation. Soc Indic Res. 1999;46(2):137-55. https://doi.org/10.1023/A:1006824100041

30. Rodrigues A, Silva JA. [The role of sociodemographic characteristics on happiness]. Psico-USF. 2010;15(1):113-23. Portuguese. https://doi.org/10.1590/S1413-82712010000100012

31. Teixeira AKM, Roncalli AG, Noro, LRA. Factors related to the dental caries incidence in youth: a cohort study in Brazilian Northeastern. Cienc Saúde Coletiva. 2016 Dec;21(12):3871-8. https://doi.org/10.1590/1413-812320152112.12582015

32. Andersen RM. Revisiting the behavioral model and access to medical care: does it matter? J Health Soc Behav. 1995 Mar;36(1):1-10. https://doi.org/10.2307/2137284

33. Jamieson LM, Mejía GC, Slade GD, Roberts-Thomson KF. Predictors of untreated dental decay among 15-34-year-old Australians. Community Dent Oral Epidemiol. 2009 Feb;37(1):27-34. https://doi.org/10.1111/j.1600-0528.2008.00451.x

34. Sheiham A, Sabbah W. Using universal patterns of caries for planning and evaluating dental care. Caries Res. 2010;44(2):141-50. https://doi.org/10.1159/000308091

35. Kim J, Choi Y, Park S, Kim JL, Lee TH, Cho KH, et al. Disparities in the experience and treatment of dental caries among children aged 9-18 years: the cross-sectional study of Korean National Health and Nutrition Examination Survey (2012-2013). Int J Equity Health. 2016 Jun;15(1):88. https://doi.org/10.1186/s12939-016-0377-x P

36. Baker SR. Applying Andersen's behavioural model to oral health: what are the contextual factors shaping perceived oral health outcomes? Community Dent Oral Epidemiol. 2009 Dec;37(6):485-94. https://doi.org/10.1111/j.1600-0528.2009.00495.x

37. Källestål C, Dahlgren L, Stenlund H. Oral health behavior and self-esteem in Swedish adolescents over four years. J Adolesc Health. 2006 May;38(5):583-90. https://doi.org/10.1016/i.jadohealth.2005.05.021

38. Sanders AE, Spencer AJ. Why do poor adults rate their oral health poorly? Aust Dent J. 2005 Sep;50(3):161-7. https://doi.org/10.1111/j.1834-7819.2005.tb00355.x

39. Araújo CS, Lima RC, Peres MA, Barros AJ. [Use of dental services and associated factors: a population-based study in southern Brazil]. Cad Saude Publica. 2009 May;25(5):1063-72. Portuguese. https://doi.org/10.1590/S0102-311X2009000500013 